with potential for multiorgan dysfunction. We feel that these potential problems with a venoarterial circuit can be minimised by maintaining high levels of systemic anticoagulation. The dose of heparin was adjusted to maintain an activated clotting time of 220-250 seconds. Despite this, there were no haematological or bleeding complications in this patient. Heparin-coated circuits and heparin-coated hollow fibre membrane oxygenators have been used for ECMO support. ${ }^{9}$ However, the impact of heparin-bonded circuits and heparin-bonded silicone membrane oxygenators (when they become available) on the adult ECMO remains to be determined.

The only ECMO-related complication in our patient was impending ischaemic damage to the limb supplied by the cannulated femoral artery. This was obviated by perfusing the distal femoral artery. For a venoarterial mode of ECMO our protocol now includes distal femoral artery perfusion and cannulation of the femoral artery and vein on different sides. The ventilatory settings whilst on ECMO also make important contributions to the overall outcome, as it is imperative to rest the damaged lung. ${ }^{5}$ During the first few days of ECMO support we kept mechanical ventilation to a minimum in order to avoid further lung injury.
We believe that extracorporeal life support techniques should be considered in rapidly progressing acute respiratory failure where (1) diagnosis has not been established but is realistically available within a short time, (2) there is a potentially treatable aetiology, (3) no comorbid disease likely to adversely affect the outcome is present, and (4) expertise in extracorporeal techniques is available.

1 Feldman C, Kallenbach JM, Reinach SG, Hurwitz MD, Thorburn JR, Koornhof HJ. Community-acquired pneumonia of diverse aetiology: prognostic features in patients admitted to an intensive care unit and a "severity of illness" score. Intensive Care Med 1989;15:302-7.

$2 \mathrm{MacF}$ arlane JT. Acute infection of lower respiratory tract. In: Weatherall DJ, Ledingham JGG, Warrell DA, eds. Oxford textbook of medicine. Vol. 15. 2nd edn. New York: Oxford Medical Publications, 1987:91-100.

3 Zapol WM, Snider MT, Hill JD. Extracorporeal membrane oxygenation in severe acute respiratory failure. A randomized prospective study. $¥ A M A$ 1979;242:2193.

4 NHLBI-NIH. Extracorporeal support for respiratory insufficiency. Bethesda, MD: DHEW Publication. 1980.

5 Gattinoni L, Pesenti A, Mascheroni D. Low-frequency positive pressure ventilation with extracorporeal $\mathrm{CO}_{2}$ removal

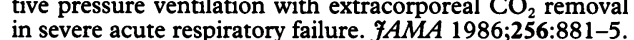

6 Anderson HL III, Delius RE, Sinard JM, McCurry KR, Shanley CJ, Chapman RA, et al. Early experience with adult extracorporeal membrane oxygenation in the modern era. Ann Thorac Surg 1992;53:553-63.

7 Bosken C, Lenfant C. Extracorporeal membrane oxygenation revisited ... again. Ann Thorac Surg 1992;53:551-2.

8 Sinard JM, Bartlett RH. Extracorporeal life support in critical care medicine. f Crit Care 1990;5:265-78.

9 Aranki SF, Adams DH, Rizzo RJ, Couper GS, DeCamp MM, Fitzgerald DJ, et al. Femoral veno-arterial extracorporeal life support with minimal or no heparin. Ann Thorac Surg 1993;56:149-55.

\section{Recombinant human DNase in management of lobar atelectasis due to retained secretions}

\author{
Bsher A Touleimat, Craig S Conoscenti, \\ Jonathan $M$ Fine
}

\begin{abstract}
Recombinant human deoxyribonuclease (rhDNase) is an agent which reduces the viscoelasticity of purulent sputum. Two cases are reported in which rhDNase was utilised for the management of lobar atelectasis due to retained purulent secretions.
\end{abstract}

(Thorax 1995;50:1319-1321)

Keywords: atelectasis, sputum, recombinant human DNase.

Abundant purulent airway secretions with resultant plugging is a common clinical problem. Conditions associated with mucus plugging include cystic fibrosis, bronchiectasis, and ineffective cough due to neuromuscular weakness. The visoelastic properties of these pur- ulent secretions are due primarily to the presence of highly polymerised, polyanionic deoxyribonucleic acid (DNA), often as extracellular fibrils. ${ }^{1}$ The major source of this DNA are the nuclei of degenerating polymorphonuclear leucocytes. ${ }^{2}$

Recombinant human deoxyribonuclease (rhDNase) hydrolyses DNA and has been shown to decrease in vitro the viscoelasticity of sputum from patients with cystic fibrosis. ${ }^{3}$ In one study the inhalation of nebulised rhDNase for six days in patients with cystic fibrosis resulted in a $10-20 \%$ improvement in forced expiratory volume in one second $\left(\mathrm{FEV}_{1}\right)$ and forced vital capacity (FVC) compared with placebo. ${ }^{4}$ In a recent long term study of patients with cystic fibrosis, daily rhDNase administration resulted in a mean improvement in $\mathrm{FEV}_{1}$ of nearly $6 \% .^{5}$

Given these encouraging results, we have used rhDNase to clear obstructing sputum in two patients with atelectasis who failed to respond to conventional therapy.

\section{Case 1}

A 33 year old man with quadriplegia was admitted with fever, chills, and cough. On physical examination he had a respiratory rate of $24 / \mathrm{min}$ and a temperature of $38^{\circ} \mathrm{C}$. Chest examination revealed decreased breath sounds. The cardiovascular system, abdomen, and extremities were normal. The admission chest 
radiograph showed atelectasis of the left lower lobe.

Upon admission he received intravenous antibiotics along with frequent chest physiotherapy. No significant change in his condition was noted after five days of therapy. Fibreoptic bronchoscopy was therefore performed which revealed thick secretions occluding the bronchus to the left lower lobe which were removed with suctioning. This was followed by chest physiotherapy and nebulised salbutamol to prevent recurrence. Nonetheless, over a period of three weeks the patient repeatedly reoccluded the left lower lobe bronchus resulting in lobar atelectasis and respiratory difficulty. He underwent four additional bronchoscopic examinations to restore patency, each achieving only partial re-expansion. On the fifth bronchoscopic examination rhDNase was instilled over the area of obstruction, resulting in liquefication of purulent secretions and removal of large amounts of sputum. A chest radiograph after bronchoscopy showed considerable improvement. The patient was discharged home the next day and treated with nocturnal nasal ventilation. A repeat chest radiograph 10 days later revealed no evidence of recurrence. The patient has been well over 4 months of follow up.

\section{Case 2}

An 82 year old man with a history of chronic obstructive pulmonary disease was admitted for management of a right hip fracture. Five days after reduction and internal fixation he underwent a right hemicolectomy to remove three cancerous lesions. His postoperative course was complicated by hypoxic respiratory failure due to collapse of the left lung. After tracheal intubation, bronchoscopy was performed which revealed purulent secretions in the left main stem bronchus. The secretions were removed by suction and aeration of the left lung was restored. Two days later he was extubated. Within 10 days, and despite chest physiotherapy, postural drainage and antibiotics, he developed collapse of the left lower lobe which necessitated further bronchoscopy to clear the sputum plug. Two days later the left lower lobe again collapsed with respiratory compromise (fig 1). On the third bronchoscopic examination thick tenacious secretions were seen obstructing the orifice to the left lower lobe bronchus. rhDNase was instilled through the bronchoscope resulting in rapid dissolution of sputum and opening of the orifice. The patient was then maintained on nebulised rhDNase twice daily for seven days with chest physiotherapy to prevent recurrence. The chest radiograph taken during the following month revealed complete resolution of atelectasis (fig 2).

\section{Discussion}

Several forms of treatment are available for management of airway occlusion and acute lobar collapse due to retained purulent secretions. Traditionally, chest physiotherapy has been used as the first modality to relieve lobar

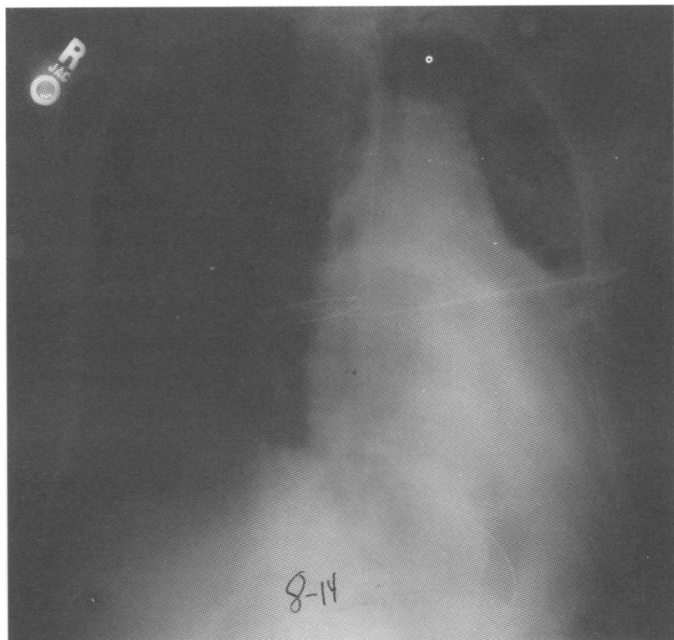

Figure 1 Chest radiograph in case 2 showing left lower lobe collapse due to mucus plugging.

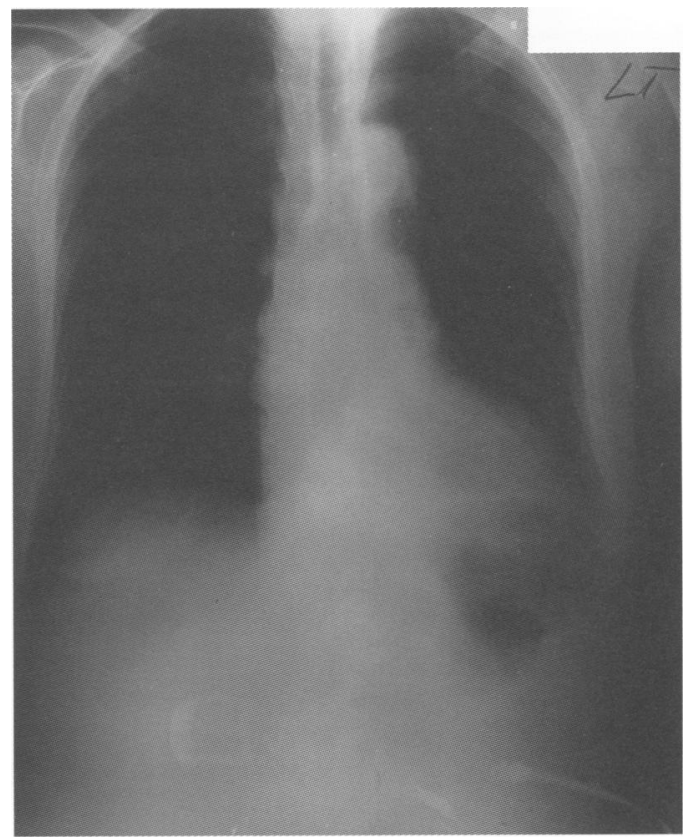

Figure 2 Chest radiograph in case 2 revealing no evidence of recurrence one month after bronchoscopy.

atelectasis. In a study of 31 patients by Marini et al there was no significant difference in restoration of lung volume between patients who underwent bronchoscopy followed by respiratory therapy and those who received respiratory therapy alone. ${ }^{6}$ One disadvantage of this study was the short follow up period of 24-48 hours. Most patients with retained secretions respond well to chest physiotherapy, antibiotics, and bronchodilators. In those who do not respond to physiotherapy, bronchoscopy has been a highly successful alternative. In addition, intermittent face mask continuous positive airway pressure (CPAP) has been advocated as an effective means of both treatment $^{7}$ and prevention ${ }^{8}$ of atelectasis.

Patients with cystic fibrosis have a high concentration of DNA in their sputum which accounts for its increased viscosity. ${ }^{2}$ Accordingly, they respond well to treatment with rhDNase. Indeed, nebulised rhDNase has been used in patients with cystic fibrosis with lobar collapse. ${ }^{9}$ 
This report suggests that directly instilled rhDNase may be one alternative to conventional therapy for lobar atelectasis. Its use may be beneficial for the subset of patients with lobar atelectasis due to retained secretions which fail to clear with vigorous coughing, chest physiotherapy, and suctioning. Direct bronchoscopic instillation offers the advantage of concentrating it at the site of obstruction and avoids the delay of waiting for the effects of nebulised administration. Further study is warranted comparing rhDNase by direct instillation and nebulisation with traditional respiratory therapy for lobar collapse due to retained secretions.

1 Armstrong JB, White JC. Liquefication of viscous purulent exudate by deoxyribonuclease. Lancet 1950;ii:739-42.

2 Potter JL, Spector S, Matthews LW, Lemm J. Studies on pulmonary secretions: III The nucleic acids in whole pul- monary secretions from patients with cystic fibrosis, bronchiectasis, and laryngectomy. Am Rev Respir Dis 1969;9. 909-16.

3 Shak S, Capon DJ, Hellniss R, Marsters SA, Baker CL. Recombinant human DNase I reduces the viscosity of cystic fibrosis sputum. Proc Nat Acad Sci USA 1990;87: 9188-92.

4 Fuchs HJ, Borowitz D, Chritiansen D, Morris E, Nash M, Ramsey B, et al. Effect of aerosolized recombinant human symptoms and on pulmonary function in patients with cystic fibrosis. $N$ Eng

5 Hubbard RC, McElvaney NG, Birrer P, Shak S, Robinson WW, Margaret CJ, et al. A preliminary study of aerosolized recombinant human deoxyribonuclease $I$ in the treatmen of cystic fibrosis. $N$ Engl f Med 1992;326:812-5.

6 Marini JJ, Pierson DJ, Hudson LD. Acute lobar atelectasis: a prospective comparison of fiberoptic bronchoscopy and respiratory therapy. Am Rev Respir Dis 1979;119:971-8.

7 Anderson JB, Olesen KP, Eikard B, Jansen E, Qvist J. Periodic continuous positive airway pressure, CPAP, by mask in the continuous positive airway pressure, CPAP, by mask in the

8 Ricksten S, Bengtsson A, Soderberg C, Thorden M, Kvist $H$. Effects of periodic positive airway pressure by mask on H. Effects of periodic positive airway pressure by mask on
postoperative pulmonary function. Chest $1986 ; 89: 774-81$. 9 Shah PL, Scott SF, Hodson ME. Lobar atelectasis in cystic fibrosis and treatment with recombinant human DNase I. Respir Med 1994;88:313-5.
Use of nebulised liposomal amphotericin $\mathrm{B}$ in the
treatment of $A$ spergillus
fumigatus empyema

\author{
Ian F Purcell, Paul A Corris
}

\begin{abstract}
A 28 year old man with asthma, bronchopulmonary aspergillosis, pulmonary thromboembolic disease, and pulmonary hypertension developed Aspergillus fumigatus empyema complicating a pneumothorax. His condition progressively deteriorated despite treatment with intravenous and intrapleural amphotericin $B$, but improved promptly after substituting nebulised liposomal amphotericin $B$ and oral itraconazole. This experience suggests that nebulised liposomal amphotericin $B$ is well tolerated and merits further assessment in the treatment of pulmonary fungal disease.
\end{abstract}

(Thorax 1995;50:1321-1323)

The Cardiothoracic Centre, Freeman Hospital, Newcastleupon-Tyne NE7 7DN,

I F Purcell

P A Corris

Reprint requests to: Dr P A Corris.

Received 13 January 1995 Returned to authors 6 March 1995 Revised version received 13 April 1995 Accepted for publication Accepted for 18 April 1995
Keywords: Aspergillus fumigatus, empyema, liposomal amphotericin B, nebuliser.

Aspergillus empyema is a rare condition which predominantly affects patients with chronic lung damage associated with previous tuberculosis and immunocompromised hosts. ${ }^{1}$ Liposomal amphotericin B (AmBisome) is an effective agent for the treatment of patients with systemic fungal disease and has been reported as having less toxicity than amphotericin when given intravenously. ${ }^{2}$ We report the first clinical use of liposomal amphotericin B delivered directly to the lungs using a nebuliser.

\section{Case report}

A 28 year old man had presented seven years previously with increasing dyspnoea. He was known to have asthma which had been well controlled and examination suggested the presence of pulmonary hypertension. Investigation including echocardiography, radionucleotide imaging, and cardiac catheterisation was performed which confirmed the presence of moderately severe pulmonary hypertension; no cause was identified. A diagnosis of unexplained or primary pulmonary hypertension was made and he was anticoagulated with warfarin.

There was a slow gradual deterioration in his exercise tolerance to New York Heart Association III over the next seven years until he presented as an emergency with severe haemoptysis. A chest radiograph at this time demonstrated a cavitating lesion in the left mid zone. His Aspergillus precipitins were strongly positive and he was referred for further assessment and management. A contrast enhanced thoracic computed tomographic scan revealed extensive central pulmonary artery thrombosis and evidence of a mycetoma within a cavity. Lower limb venography showed the presence of venous thrombosis and the cause of his pulmonary hypertension was diagnosed as chronic subacute massive pulmonary embolism. The source of the haemoptysis was thought to be an aspergilloma within an old cavitating pulmonary infarct. Bronchial angiography with embolisation of the vessels supplying the cavity was performed, followed by right heart catheterisation and infusion of streptokinase and plasminogen directly into the pulmonary artery. ${ }^{3}$ There was no change in his pulmonary vascular resistance or pressure and pulmonary endarterectomy and insertion of an 